\title{
The Phenomenon of Research and Development Method in Research of Software Engineering
}

\author{
Mufadhol Mufadhol ${ }^{\mathrm{a}, 1, *}$, Siswanto Siswanto ${ }^{\mathrm{a}, 2}$, Djarot Dian Susatyono ${ }^{\mathrm{b}, 3}$, Maya Utami Dewi ${ }^{\mathrm{b}, 4}$ \\ ${ }^{a}$ Departement of Computer System, STEKOM Semarang, Indonesia \\ ${ }^{b}$ Departement of Computer Engineering, STEKOM Semarang, Indonesia \\ a,b Jl. Majapahit 605 Pedurungan Semarang 50142, Indonesia, Phone/Fax (024)6723456 \\ ${ }^{1}$ masyong29@gmail.com, ${ }^{2}$ webmaster@syswebco.com, ${ }^{3}$ jarot1941@gmail.com, ${ }^{4}$ maya@stekom.ac.id \\ * corresponding author
}

\section{ARTICLE INFO}

Article history:

Received : 04/25/2017

Revised : 05/06/2017

Accepted : 05/10/2017

Keywords:

Phenomenon

research and development

method

software engineering

\section{ABSTRACT}

Progress of science and technology is very influential to development of software engineering. Communication between software developers and prospective users of software engineering by prototype system is very important in the development of software engineering. Research and Development method in research of software engineering is very suitable be used because supports the existence of such communications. But it is found there are several research that use this method with not perfect or not completed, so research results produced less fit with purpose. This paper will be explain how to used the stages must be carried out in research of software engineering with the method of research and development, in order to make the research more be effectively and efficiently as well as software development efforts that simultaneously accompanied by the validation effort for the results to be achieved in accordance with the expected goals.

Copyright @ 2017 International Journal of Artificial Intelegence Research. All rights reserved.

\section{Introduction}

Software engineering or software development that will produce prototype requires a special way so that the system can be developed in accordance with the wishes and needs of potential users [1-3]. Selection of a research study methods especially in research related to the development of software engineering should be appropriate to the problem and faced and not to create new problems [4], it is because of many selection methods in software engineering research [15]. Methods of research and development in research related to software engineering allow their interaction as a means of communication between software developers with prospective users of engineering software through prototype software before it becomes a final product [1,6]. Model research and development in software engineering research methods is to produce a product and also to test the effectiveness of these products through a validation test and review by conveying in a seminar or discussion forums together and prioritize the independence of the software developer [6-8]. Of the some research, they are not exhaustive and only use a few stages just in research methods research and development, so that the end result of the research is less than optimal and it is not fit for purpose and there are some errors or defects in the resulting product.

\section{Research Method}

A. Software Engineering

The influence of the software which has spread to many aspects of life ranging from business, education, health, technology and even the military world is already unavoidable towards the use of the software [9-10]. The software built from elements of syntax and Symantec is realized in the form of coding program and instructions which will be forwarded and executed into a machine language which will be the control center of the work of a CPU [10]. 


\section{B. A Research of Software Engineering}

Research Methodology is the field of study focusing on methods of a research [11]. The success of software engineering research is highly dependent on the suitability of the selection method in a study [4,5]. Research conducted both qualitatively and quantitatively automatically forms a pattern of software engineering research constructively especially if they are complementary [11], so it will be able to generate a software engineering that can provide a framework to build a better quality software.

\section{Method of Research and Development}

A Study of the Research and Development is a study that is used to produce a certain product and at the same time to test the effectiveness of the products produced through the steps or stages of refinement of $[6,8]$. Independence of a researcher without any pressure from others who have an interest to determine the types and sources of data in the study by using research and development to determine the quality of the research results [8]. The validation process which is the stage of product testing in research methods and developmrnt can engage potential users to specify results to be achieved and determine the level of accuracy in the study [7].

\section{Result and Discussion}

\section{A. The Relevance of Science And Technology}

The development of software engineering can always find something or a new product and is strongly influenced by developments in science and technology globally [9]. Software engineering that is part of the discipline of computer science can be used to assist the needs of human life. It is a fact that humans have toward a new era called the digital era. In the digital era, the presence and the existence of a software is needed by humans $[1,9]$. Software engineering relationship with science and technology can be described as in Figure 1.

\section{B. The Determination Of Need And Design Communication}

After the prospective users of software engineering determine the needs that have been noted and incorporated in full by the researcher or developer and software engineering will usually be drawn up preliminary designs of several times demand change models of potential users to the researcher or developer and manufacturer of software engineering which will be tailored to the needs and wants of the user in the form of prototype [10]. Methods of research and development can be used in software engineering for systems development methods of communication between the manufacturer recommends the system in this case was a researcher or software makers to potential users through prototype software engineering [6,7]. Communication with prospective users of the software can be done by using paper as the initial scheme which describes the interaction to accommodate at once to accommodate the needs of users of software that may occur. Utilization of a simple program that is temporary can also be used as an alternative option in case the scheme through the use of less paper can accommodate and meet the needs of potential users of a product of software engineering [1].

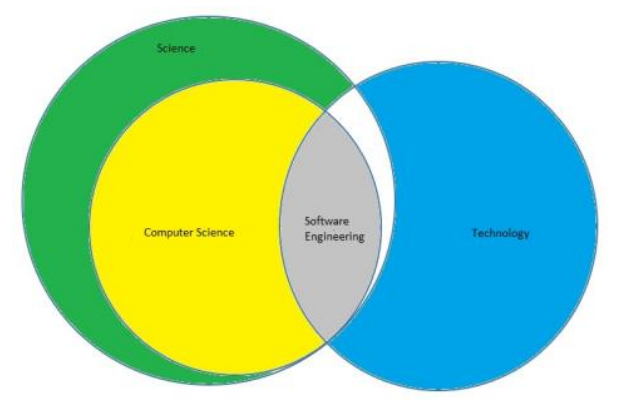

Figure 1. Software Engineering in science and technology

\section{The Stage of Research and developmnet Method}

To obtain a good product research, the process of research conducted should adhere to the following procedures on the system development methods to be used. In software engineering research that uses methods of systems development research and development, researchers must carry out all stages in the process of research and development methods [6-7]. like figure 2, as follows:

- Research and information collecting. At this early stage researchers should collect all information related to the research including conducting needs analysis, literature, beginning smallscale research and reporting standards to be used. 


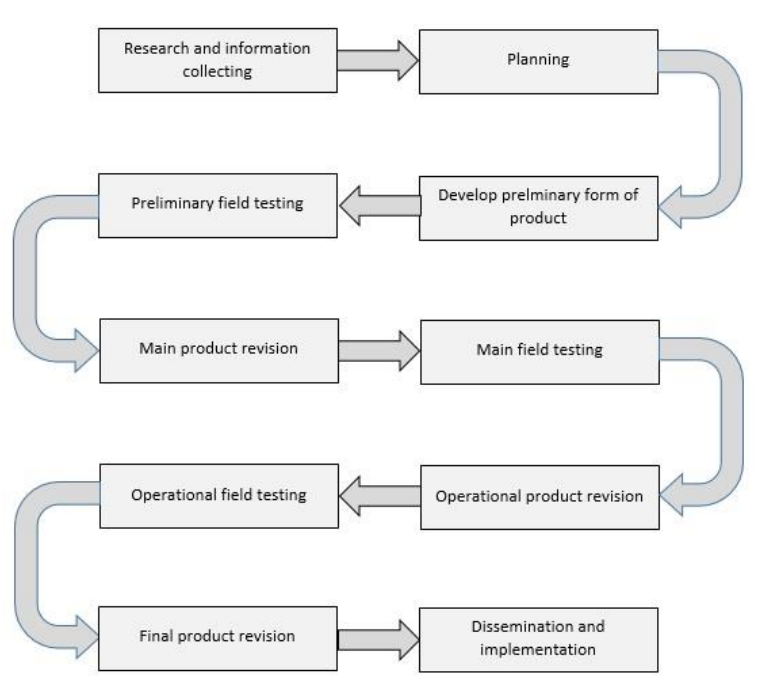

Figure 2. The Level of Research and Development

- Develop prelminary form of product. The next stage is to create a product design research that will be developed, determining the facilities and infrastructure for research and development process, determine the implementation of trials in the field of product design and determine the job description of each of the parties involved in the research process.

- Preliminary field testing. The next phase is a trial of product design research on a limited basis. In this step the researcher needs to do early trials of the research in the field of temporary product design . Products in field trials early stage is conducted repeatedly in order to obtain a design according to the substance and methodology

- Main product revision. This stage is an improvement of the product model or the initial design that has been tested by field trials in a temporary and limited manner. Repairment and improvement of the initial product should be done more by using a qualitative approach. Evaluations performed at this stage are the evaluation of the implementation process of design creation, resulting in improvements and enhancements that will be done is internal

- Main field testing. At this stage, researchers can test the product research more broadly. This step is performed to test the effectiveness of the design of the product. Tests on product design effectiveness by the field test will be obtained more complete product design so that it can be in accordance with the wishes of potential users of software engineering

- Operational product revision. This stage is the second stage of repairment after testing a wider field. Refinement and improvement of the research products of the field test at this stage will be more focused towards development, it is because at this stage of the previous field trials carried out by their control in the form of questions. Questions used were pretest and posttest. Refinement and improvement of products will be based on the evaluation of the results obtained so that the approach used is a quantitative approach

- Operational field testing. In this step, the researchers should conduct testing on a large scale to test the effectiveness and adaptability of the design of the products produced. The test of effectiveness and adaptability of product design research involves prospective users of the product in the form of software engineering. The results of field testing of this phase will obtain design models for readily applied software engineering products.

- Final product revision. At the final stage, researchers as well as developers and software makers will further refine the results of research products in the form of software engineering that is being developed. Completion of the end product of a software engineering is considered necessary to ensure the accuracy and validity of the products developed, so at this stage, it will ne already obtained a product of software engineering that level of effectiveness and accuracy is reliable and accountable.

- Dissemination and implementation. Researcher is demanded to convey and to discuss the results of research in the form of software engineering through scientific forums or publish research results through mass media, both print and electronic media and engineering products are required to 
distribute the software after going through the process of quality control

\section{Product Validations}

Product testing can be done through individual validator or potential users of software engineering. The first stage of testing can be by testing the initial design or design validation system, then the second phase of testing is testing the product by potential users of software engineering. Testing and validation use a questionnaire research instrument in form to the validator. Form for this validator is an assessment of the product design engineering software in terms of several aspects of the indicators. The assessment indicators are assumed to select a number corresponding to the value criteria given numbers 1 to vote not / less, number 2 for between yes and no votes, the number 3 represents a fairly good ratings and 4 to give a good or appropriate assessment. The number of questions is adjusted to the needs and the number of potential users of the software engineering. This validator of the form value will be based on the scores. Description scores and grades are given in Table 1 .

Table 1. Score and Grade Validation Form

\begin{tabular}{|c|l|}
\hline \multicolumn{1}{|c|}{ Skor } & \multicolumn{1}{|c|}{ Grade } \\
\hline $1<\mathrm{n}<10$ & Not Good \\
\hline $11<\mathrm{n}<20$ & Fair \\
\hline $21<\mathrm{n}<30$ & Good \\
\hline $31<\mathrm{n}<40$ & Very Good(valid) \\
\hline
\end{tabular}

The final result can be known through concluded information, whether the design of the products already meets or corresponds with the need by prospective users of software engineering or not. Through these scores can also conclude whether the modified software is valid or not. Conclusions validation results can be seen in table 2 .

Table 2. Conclusion Of Validation Result

\begin{tabular}{|c|l|}
\hline No & \multicolumn{1}{|c|}{ Remarks } \\
\hline 1 & It can't be used and must be replaced \\
\hline 2 & It can be used and needs many adjustments \\
\hline 3 & It can be used and needs little adjustments \\
\hline 4 & It can be used without revision \\
\hline
\end{tabular}

Form validation sheet is expected to have a column for comments and suggestions for improvements, so that they can be useful for the developer in the improvement of software products developed.

\section{CONCLUSION}

A study method of Research and development can be used in software engineering research, because it supports the communication between software developers with prospective users of engineering software through prototype system. The linkage between stages one to the other ones as well as the importance of each stage in this method, the researchers must carry out all stages of the process in order to achieve an optimal research results. Validation can be done by prospective users of software engineering by giving a vote that will determine the product developed is feasible to use so that research can be more effective and efficient.

\section{References}

[1] Roger, S. P. Software Engineering: A Practitioner's Approach. 7th ed. The McGraw Hill Companies. New York. USA. 2010.

[2] Michael, D., et al. Distributed Software Engineering in collaborative Research Projects. Proc 10th. IEEE. Internatioanl Conference on Global Software Engineering. Pp:105-109. Ciudad Real. Spain. july 2015.

[3] Mufadhol, M., et al. Netscan and Networx for Management Bandwidth and Traffic with Simple Routing. Journal of TELKOMNIKA Telecommunication, Computing, Electronics and Control. Vol. 15(1). Pp: 464-470. 2017.

[4] Sarah, B., et al. Making Software Engineering Research Relevant. IEEE Computer Society. Vol. 47(4). Pp: 80-83. 2014

[5] ACM SIGSOFT. The Future of Software Engineering Research. FSE-18. International Symposium on The Foundations of Software Engineering. U.S. 2011.

[6] Gajbhiye, B. N., Prasad, V. K. Model for Defence R\&D Scientific and Engineering Software Development. International Journal of Lecture Notes on Software Engineering. Vol. 1(3). Pp: 319-322. 2013.

[7] Yang, M. S., et al. An Analisys of National R\&D Collaborators Network based on The NTIS Data. International Journal of Software Engineering and Applications. Vol. 8(11). Pp: 11-24. 2014.

[8] Jung, C. F., et al. A Method of R\&D Electronic Produc for Application by Independent Engineers, Designers and Inventors. Brazilian Journal of Operations \& Production Management, Vol. 7(2). Pp: 153173. 2010. 
[9] NESI. Software Engineering Key Enabler for Innovation. Networked European Software and Services Initiative. EUROPE. July 2014.

[10] Gary, Born. Controlling Software Quality. Software Engineering Journal. Vol. 1(1). Pp: 24-28. 2009.

[11]Heri Nurdiyanto, Hermanto Hermanto, "Signature Recognition using Neural Network Probablisitc", International Journal of Advances in Intelligent Informatics, Vol. 2, Issue 1, pp. 46-53, 2016 